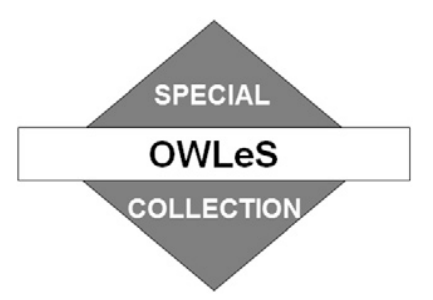

\title{
Influence of Lake Erie on a Lake Ontario Lake-Effect Snowstorm
}

\author{
DAvid A. R. Kristovich, Luke BARD, And Leslie Stoecker \\ Climate and Atmospheric Science Section, Division of State Water Survey, Prairie Research Institute, \\ University of Illinois at Urbana-Champaign, Urbana, Illinois \\ BART GEERTS \\ Department of Atmospheric Science, University of Wyoming, Laramie, Wyoming
}

(Manuscript received 15 December 2017, in final form 11 July 2018)

\begin{abstract}
Annual lake-effect snowstorms, which develop through surface buoyant instability and upward moisture transport from the Laurentian Great Lakes, lead to important local increases in snowfall to the south and east. Surface wind patterns during cold-air outbreaks often result in areas where the air is modified by more than one Great Lake. While it is known that boundary layer air that has crossed multiple lakes can produce particularly intense snow, few observations are available on the process by which this occurs. This study examines unique observations taken during the Ontario Winter Lake-effect Systems (OWLeS) field project to document the process by which Lake Erie influenced snowfall that was produced over Lake Ontario on 28 January 2014. During the event, lake-effect clouds and snow that developed over Lake Erie extended northeastward toward Lake Ontario. OWLeS and operational observations showed that the clouds from Lake Erie disappeared (and snow greatly decreased) as they approached the Lake Ontario shoreline. This clear-air zone was due to mesoscale subsidence, apparently due to the divergence of winds moving from land to the smoother lake surface. However, the influence of Lake Erie in producing a deeper lake-effect boundary layer, thicker clouds, increased turbulence magnitudes, and heavier snow was identified farther downwind over Lake Ontario. It is hypothesized that the combination of a low-stability, high-moisture boundary layer as well as convective eddies and limited snow particles crossing the mesoscale subsidence region locally enhanced the lake-effect system over Lake Ontario within the plume of air originating over Lake Erie.
\end{abstract}

\section{Introduction}

Forecasts of lake-effect snowstorms have become increasingly accurate as numerical atmospheric simulations have improved. However, critical details of the mesoscale structure, spatial and temporal distribution of snowfall, snowband movement, and precipitation intensity continue to be difficult to predict (e.g., Niziol et al. 1995). Much of the forecast difficulty is due to smaller-scale processes within the lake-effect boundary layer (Saslo and Greybush 2017), many of which have highly limited observational datasets for development and evaluation of simulations. Indeed, multiple studies have documented the sensitivity of lake-effect snowstorm simulations on what boundary layer and

\footnotetext{
Corresponding author address: David Kristovich, dkristo@illinois. edu
}

microphysical schemes are chosen (e.g., Ballentine et al. 1998; Theeuwes et al. 2010; Reeves and Dawson 2013; Conrick et al. 2015). Difficulty in simulating complex processes involved in lake-effect development may be greater along the eastern lakes where lake-effect snowbands are often the result of the combined influence of both the local lake and upwind lakes [as evidenced by so-called lake-to-lake (L2L) bands; Rodriguez et al. 2007]. This study seeks to improve our understanding of these L2L interactions through analyzing some of the first detailed observations of lakeeffect convection over Lake Erie influencing lake-effect snowbands over Lake Ontario.

Lake-effect cloud bands extending from one of the Laurentian Great Lakes to another have been noted since early in the satellite era, in visible photographs from the TIROS and Environmental Science Services 
Administration (ESSA) satellites (Holroyd 1971). One of the earliest published articles that identified how the presence of an upwind lake influenced local (downwind) lake-effect snowbands was that of Agee and Gilbert (1989), who showed that regions of "unusually deep" convective boundary layers over Lake Michigan could be traced to regions where the air had previously passed over Lake Superior. As noted by multiple authors, L2L bands can produce particularly intense snowfall over and near the downwind lake (i.e., Niziol et al. 1995; Sousounis and Mann 2000; Rodriguez et al. 2007; Ackerman et al. 2013). Mann et al. (2002) classified the influences of boundary layer modification from upwind lakes as either "direct" or "synergistic (indirect)." The latter type of influence, whereby regional-scale wind flows are altered by the influence of multiple Great Lakes, affects convective locations and intensity on each lake. The current study focuses on those influences that Mann et al. classified as direct.

The most commonly cited processes by which upwind lakes are thought to have a direct influence on lake-effect convection over a downwind lake (Niziol et al. 1995; Rose 2000; Rodriguez et al. 2007; Cordeira and Laird 2008) include 1) development of a low-stability, humid layer through mixing over the upwind lake, which allows the downwind lake-effect boundary layer to deepen and produce clouds rapidly (e.g., Agee and Gilbert 1989; Ballentine et al. 1998), and 2) maintenance of the circulation from a lake-effect snowband from an upwind lake as it crosses over the intervening land surface and provides a "boost" to convective circulations over the downwind lake (e.g., Rose 2000; Wright et al. 2013; Deacu et al. 2012). Such processes have been shown to be important for interactions between the Great Lakes and smaller downwind lakes (e.g., Laird et al. 2010).

Rose (2000) examined the possibility that development of gravity waves in the stable air above the convective layer as a result of land-lake frictional differences, such as those modeled by Yuen and Young (1986), could enhance convective depth if the upwardmoving portions of the gravity waves occur over the downwind lake. However, satellite and radar observations do not often indicate periodic patterns in clouds or snow on scales of multiple lakes, as would be expected with such gravity wave influences. Given the wide range of atmospheric and surface conditions influencing gravity wave location and intensity, it seems unlikely that the needed specific placement of the gravity waves occurs frequently enough to explain the common upwind lake influences. It is also feasible that seeding of the downwind lake-effect clouds by snow produced by upwind snowbands could enhance snow production over the downwind lake. Natural cloud seeding by snow produced above a lake-effect boundary layer was found to greatly increase snowfall rates in specific locations (Schroeder et al. 2006). However, large concentrations of snow particles from an upwind lake have not been reported near a downwind lake. With air temperatures well below $0^{\circ} \mathrm{C}$ at cloud height, there is no known mechanism for snow particles contributing significantly to liquid cloud. Whether snow particles in adequate concentrations could remain airborne and not evaporate between the individual lakes also needs to be further examined.

This study investigates changes in the atmospheric boundary layer that occurred as the lake-modified air from Lake Erie flowed across northwestern New York State and then over Lake Ontario on 28 January 2014. Observations taken during the Ontario Winter Lakeeffect Systems (OWLeS) field project are examined to determine whether the Lake Erie lake-effect plume had an influence on subsequent development of lake-effect convection over Lake Ontario.

\section{Method}

Data for this investigation were collected as part of the OWLeS field campaign. Details of the field campaign are provided in Kristovich et al. (2017). Some information from that article is relevant to the current investigation and is repeated here for the readers' convenience.

The University of Wyoming King Air (UWKA) aircraft collected a critical dataset for this investigation. The flight track carried out by the UWKA, illustrated in Fig. 1, collected observations in three regions: 1) upwind of Lake Ontario [subsequently called the "upwind planetary boundary layer" (UPBL)], 2) over and close to the Lake Ontario shorelines ["shoreline transitional PBL" (STPBL)], and 3) over Lake Ontario ["Ontario lake-effect PBL" (OPBL)]. As will be shown later, the flight stacks oriented approximately perpendicular to the wind direction (A, C, E, and G in Fig. 1) had portions both within and outside the Erie lake-effect plume of modified air. The entire sawtooth pattern was flown three times by the UWKA at near-constant heights of $0.8,1.4$, and $1.9 \mathrm{~km}$ AGL. The naming convention used in this paper and additional information on each flight leg are given in Tables 1 and 2.

The UWKA carried a wide range of both in situ and remote sensing instrumentation during OWLeS. Detailed information on UWKA instrumentation can be found online (http://www.atmos.uwyo.edu/uwka/). Analyses of data taken by the Wyoming Cloud Radar (WCR) were conducted using software provided by the University of Wyoming and additional analysis tools 


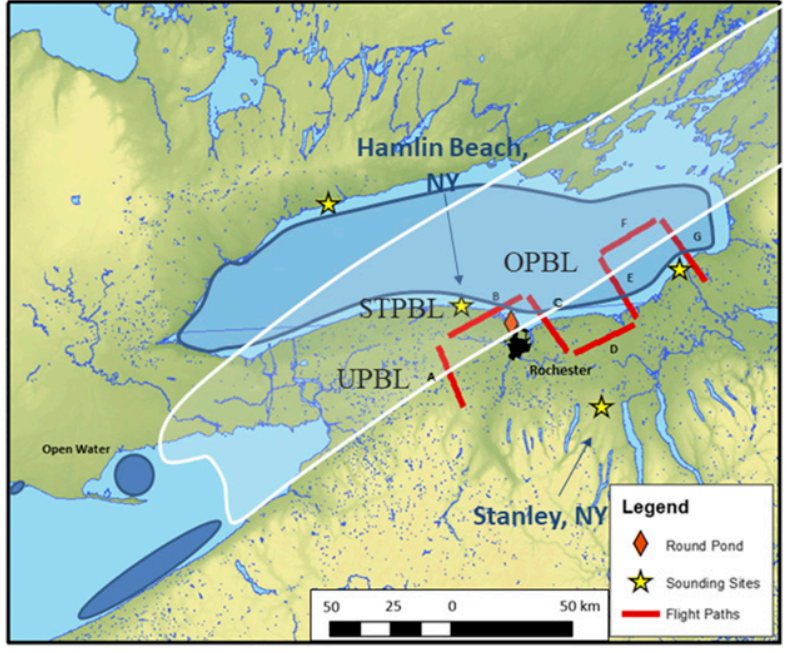

FIG. 1. Locations of key observation platforms on 28 Jan 2014. The approximate trajectory of boundary layer air modified by Lake Erie is illustrated by light white shading. Flight stacks flown by UWKA are shown as red lines. Background shading denotes elevation variations. Light blue denotes the locations of lakes and major rivers, while darker blue patches over Lake Erie and the outlined somewhat darker blue region over Lake Ontario indicate regions of open water as indicated by MODIS imagery from $27 \mathrm{Jan}$ 2014. As defined and described more fully in the text, UPBL, STPBL, and OPBL denote regions with upwind, shoreline transitional, and Lake Ontario planetary boundary layers, respectively.

developed at the University of Illinois at UrbanaChampaign. The WCR operates at $95 \mathrm{GHz}(3-\mathrm{mm}$ wavelength), providing detailed information on the profile of equivalent radar reflectivity and vertical movement of the precipitation directly above and below the aircraft (Wang et al. 2012). The Wyoming Cloud Lidar (WCL) also collected data that were analyzed with the University of Wyoming software.

Analysis of in situ observations was conducted using MATLAB, version 9.0.0.341360 (number R2016a), and Microsoft, Inc., Excel (version 2016). All in situ and remote sensing observations were corrected for known errors by the University of Wyoming and the National Center for Atmospheric Research Earth Observation Laboratory. It is desirable to determine the apparent influences of the UPBL from Lake Erie on the OPBL. This was accomplished by examination of WCR-observed reflectivity, vertical velocity, and turbulence intensity in 1-min intervals (approximately 5-km horizontal distance) along each crosswind flight leg at a height of $1.9 \mathrm{~km}$ (legs A3, C3, E3, and G3) and with in situ particle and thermodynamic observations along the lower two flight legs.

Relative turbulence intensity profiles were estimated by calculating the vertical component of the turbulence kinetic energy $\left(\mathrm{TKE}_{w}\right)$ on the basis of the Doppler velocity measurements from the WCR. For each height (radar range gate, converted into height above the surface) along each 1-min interval, $\mathrm{TKE}_{w}$ was determined by 1 ) calculating average vertical motion using the time series of perturbation vertical velocities $w^{\prime}$ for each height and 2) calculating the turbulent kinetic energy (TKE) per unit mass $m$ for each height:

$$
\mathrm{TKE} / m=0.5\left(\overline{w^{12}}\right) .
$$

Five university-owned sounding units were deployed during OWLeS, four of which operated on 28 January 2014: the Millersville University Vaisala, Inc., system at the Finger Lakes Technical and Career Center in Stanley, New York; the State University of New York at Oswego Vaisala system in Oswego, New York; the University of Illinois GRAW Radiosondes GmbH system at Darlington Provincial Park, Ontario, Canada; and the Hobart and William Smith GRAW system in Hamlin Beach, New York (Fig. 1). The Vaisala sites launched RS92-SGP radiosondes (MW41 ground station software), and the GRAW sites launched DFM-09 radiosondes (GRAWmet 5, version 5.9.3.4, ground station software). Soundings were taken at 1215 and 1515 eastern standard time (EST) at all four locations. Visualization and analyses of these data were completed with the Rawinsonde Observation Program ("RAOB"), version 6.8 , for the Windows operating system.

Descriptions of synoptic conditions were derived from surface and upper-level maps and data that were available online. These were obtained from the University of Wyoming (http://weather.uwyo.edu/) and the National Center for Atmospheric Research (http://weather.rap. ucar.edu/).

\section{Results}

The lake-effect event under investigation developed within an Arctic air mass that overspread the eastern Great Lakes region behind a cold front that crossed during the morning of 27 January 2014. Behind this cold front, a deep trough extended southward from a slowmoving cyclone centered in the vicinity of Hudson Bay in Canada. By 1200 UTC on the day that observations were taken, 28 January, the surface trough extended southward to near Lake Michigan (Fig. 2) while above approximately $700 \mathrm{hPa}$ the trough intersected the western Great Lakes area. This trough and high pressure to the east provided persistent near-surface southwesterly winds in the Lake Erie-Ontario region through much of the day on 28 January, ideal for lake-effect snows over the eastern Great Lakes. Over Lake Ontario, two primary lake-effect features were evident in regional radar 
TABLE 1. Characteristics of the flight legs composing flight stacks A-G as shown in Fig. 1.

\begin{tabular}{|c|c|c|c|c|}
\hline Flight legs & Alt (km AGL) & Pressure $(\mathrm{hPa})$ & Time interval start, end (UTC) & Time of shore crossing (UTC) \\
\hline \multicolumn{5}{|c|}{$\mathrm{A}\left(42.90^{\circ} \mathrm{N}, 77.99^{\circ} \mathrm{W}-43.19^{\circ} \mathrm{N}, 78.13^{\circ} \mathrm{W}\right)$} \\
\hline A3 & 1.9 & 790 & $1750: 53,1758: 40$ & - \\
\hline A2 & 1.4 & 850 & $1952: 30,2000: 33$ & - \\
\hline A1 & 0.8 & 920 & 1941:07, 1949:01 & - \\
\hline \multicolumn{5}{|c|}{$\mathrm{B}\left(43.23^{\circ} \mathrm{N}, 78.06^{\circ} \mathrm{W}-43.39^{\circ} \mathrm{N}, 77.57^{\circ} \mathrm{W}\right)$} \\
\hline B3 & 1.9 & 790 & 1800:05, 1806:58 & 1804:31 \\
\hline $\mathrm{B} 2$ & 1.4 & 850 & 2001:10, 2009:15 & 2006:34 \\
\hline B1 & 0.8 & 920 & $1928: 31,1940: 37$ & 1932:13 \\
\hline \multicolumn{5}{|c|}{$\mathrm{C}\left(43.39^{\circ} \mathrm{N}, 77.53^{\circ} \mathrm{W}-43.12^{\circ} \mathrm{N}, 77.30^{\circ} \mathrm{W}\right)$} \\
\hline $\mathrm{C} 3$ & 1.9 & 790 & $1807: 28,1813: 55$ & 1810:16 \\
\hline $\mathrm{C} 2$ & 1.4 & 850 & 2009:44, 2016:19 & $2012: 34$ \\
\hline $\mathrm{C} 1$ & 0.8 & 920 & 1920:01, 1927:28 & $1924: 22$ \\
\hline \multicolumn{5}{|c|}{$\mathrm{D}\left(43.11^{\circ} \mathrm{N}, 77.26^{\circ} \mathrm{W}-43.22^{\circ} \mathrm{N}, 76.86^{\circ} \mathrm{W}\right)$} \\
\hline D3 & 1.9 & 790 & $1814: 28,1820: 14$ & - \\
\hline D2 & 1.4 & 850 & 2016:50, 2022:50 & - \\
\hline D1 & 0.8 & 920 & 1910:46, 1919:34 & - \\
\hline \multicolumn{5}{|c|}{$\mathrm{E}\left(43.25^{\circ} \mathrm{N}, 76.84^{\circ} \mathrm{W}-43.54^{\circ} \mathrm{N}, 77.05^{\circ} \mathrm{W}\right)$} \\
\hline E3 & 1.9 & 790 & $1820: 50,1828: 28$ & 1822:04 \\
\hline E2 & 1.4 & 850 & $2023: 25,2031: 23$ & $2024: 42$ \\
\hline E1 & 0.8 & 920 & 1902:34, 1910:17 & 1909:07 \\
\hline \multicolumn{5}{|c|}{$\mathrm{F}\left(43.56^{\circ} \mathrm{N}, 77.04^{\circ} \mathrm{W}-43.69^{\circ} \mathrm{N}, 76.67^{\circ} \mathrm{W}\right)$} \\
\hline F3 & 1.9 & 790 & 1829:09, 1834:20 & - \\
\hline $\mathrm{F} 2$ & 1.4 & 850 & 2032:01, 2037:41 & - \\
\hline $\mathrm{F} 1$ & 0.8 & 920 & $1853: 10,1902: 04$ & - \\
\hline \multicolumn{5}{|c|}{$\mathrm{G}\left(43.69^{\circ} \mathrm{N}, 76.63^{\circ} \mathrm{W}-43.39^{\circ} \mathrm{N}, 76.38^{\circ} \mathrm{W}\right)$} \\
\hline G3 & 1.9 & 790 & $1834: 50,1841: 48$ & 1839:17 \\
\hline $\mathrm{G} 2$ & 1.4 & 850 & 2038:10, 2045:10 & 2043:08 \\
\hline G1 & 0.8 & 910 & $1844: 14,1852: 41$ & 1847:41 \\
\hline
\end{tabular}

composites and visible satellite imagery: an intense lakeeffect cloud and snowband downwind from the westernmost edge of the lake and a wide area of shallower lake-effect clouds over the southeastern half of the lake.

The synoptic pattern is very similar to the "West[erly]-Strong" synoptic type described by Ellis and Leathers (1996). This relatively infrequent synoptic type was found by Ellis and Leathers to provide the heaviest average lake-effect snowfall east of Lake Ontario, as well as colder $850-\mathrm{hPa}$ temperatures than any other pattern, and strong surface winds with a westerly component. On 28 January, $850-\mathrm{hPa}$ temperatures were colder than the average West-Strong synoptic type $\left(-26^{\circ} \mathrm{C}\right.$ as compared with $\left.-20^{\circ} \mathrm{C}\right)$, producing superadiabatic lapse rates between the lake surface $\left(0^{\circ}-2^{\circ} \mathrm{C}\right)$ and overlying air. Suriano and Leathers (2017) identified the "SW-1" lake-effect synoptic type (identified as predominantly southwesterly winds) that included strong

TABLE 2. Spatial characteristics of the flight stacks shown in Fig. 1.

\begin{tabular}{cccc}
\hline \hline Flight stack & Length $(\mathrm{km})$ & $\begin{array}{c}\text { Downwind fetch from the } \\
\text { eastern shore of } \\
\text { Lake Erie }(\mathrm{km})^{\mathrm{a}}\end{array}$ & $\begin{array}{c}\text { Downwind fetch from } \\
\text { the western shore of } \\
\text { Lake Ontario }(\mathrm{km})^{\mathrm{b}}\end{array}$ \\
\hline A & 37 & 69 & - \\
B & 44 & 99 & - \\
C & 35 & 127 & -15 \\
D & 35 & 152 & 58 \\
E & 37 & 168 & - \\
F & 33 & 185 & 97
\end{tabular}

\footnotetext{
a Approximate; at track midpoint.

${ }^{\mathrm{b}}$ This is the estimated track midpoint distance from Round Pond, New York, northwest of Rochester, New York. Note that only northern portions of the pass are downwind from the Lake Ontario shoreline (see Fig. 1).
} 


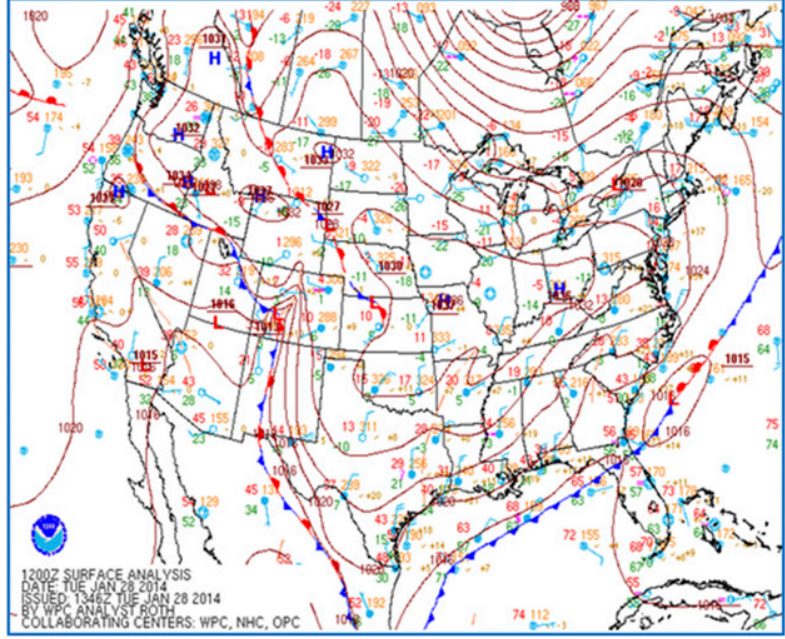

FIG. 2. NOAA surface analysis for 1200 UTC 28 Jan 2014.

troughing over the western Great Lakes similar to that seen on 28 January.

In the region where OWLeS observations were taken, surface winds were from the WSW. Terra MODIS imagery from 1550 UTC 28 January (Fig. 3), animations of GOES-13 imagery, and the NOAA WSR-88D in Buffalo, New York (KBUF; not shown), indicate that clouds and snow originated over Lake Erie and stretched parallel to the wind to south-central Lake Ontario. Surface observations confirmed that, throughout the morning of 28 January, skies were clear west and south of Lake Erie and persistent low-level clouds extended from Lake Erie to Lake Ontario. It might be expected that, since Lake Erie was $>95 \%$ ice covered (GLERL 2017), lake-effect convection would be unlikely. However, observations from Gerbush et al. (2008) indicated that weak upward heat and moisture fluxes can occur even over icecovered areas of Lake Erie. In addition, MODIS imagery from 27 January (not shown) indicated two regions of open water or thin ice: in northern portions of the central and eastern basins and along most of the southern shore. We hypothesize that weak surface heat and moisture fluxes over much of Lake Erie combined with stronger fluxes over the open water/thin ice regions to produce the WSW-ENE-oriented cloud region (Fig. 3).

The following three sections describe the PBL from between Lakes Erie and Ontario (section 3a), in the shoreline region (section $3 b$ ), and over Lake Ontario (section 3c).

\section{a. PBL upwind of Lake Ontario (UPBL)}

As discussed above, multiple observations indicated that a region (plume) of lake-effect clouds and snow originated over Lake Erie (Fig. 3) and extended ENE

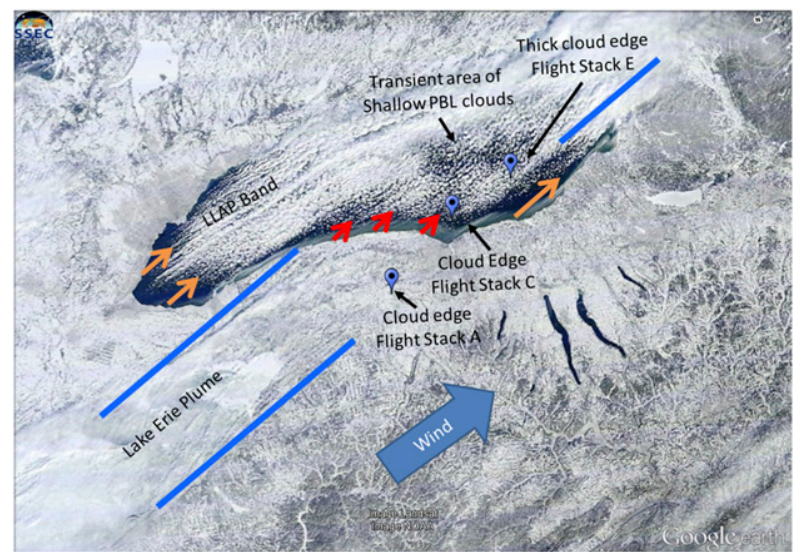

FIG. 3. Visible imagery from Terra MODIS from 1548 UTC 28 Jan 2014 (see also Kristovich et al. 2017). The approximate PBL wind direction is indicated. Dark blue lines indicate the northwestern and southeastern edges of the plume of air modified by Lake Erie in the UPBL and the southern edge of the thicker lakeeffect clouds over eastern Lake Ontario. The southernmost edges of the clouds from UWKA photographs in the UPBL and STPBL in flight stacks $\mathrm{A}$ and $\mathrm{C}$ are indicated, along with the edge of deep lake-effect clouds along flight stack E in the OPBL. Arrows indicate the approximate fetch distance from the upwind shore of Lake Ontario to the first lake-effect clouds over the lake. The significance of the colors of the arrows is explained in section 3c.

over land areas in northwestern New York State on 28 January 2014. Visible satellite imagery indicated that both the northwestern and southeastern edges of the cloudy region (thick blue lines in Fig. 3) exhibited little transverse motion throughout the daylight hours. While the clouds are somewhat difficult to see over portions of the land area upwind of Lake Ontario, photographic images from the UWKA showed that the location of the southeastern edge of the clouds along flight stack A (indicated in Fig. 3) was directly downwind from the southeastern edge that was evident closer to Lake Erie.

KBUF WSR-88D and regional NOAA surface observations indicated that the cloudy region ENE of Lake Erie was accompanied by widespread snow showers for most of the period of OWLeS operations on this date. NOAA satellite visible and IR imagery and radar reflectivity animations indicate a decrease in cloudiness and snowfall starting during the final $15 \mathrm{~min}$ of the flight, which may have influenced observations in flight legs F2 and G2. Since these two flight legs were conducted outside the quasi-steady-state lake-effect environment, they were not used in this study.

Research radiosonde soundings taken at locations indicated in Fig. 1 at 1715 and 2015 UTC offer the opportunity to compare conditions within and outside the cloudy region downwind of Lake Erie. Figure 4 shows 

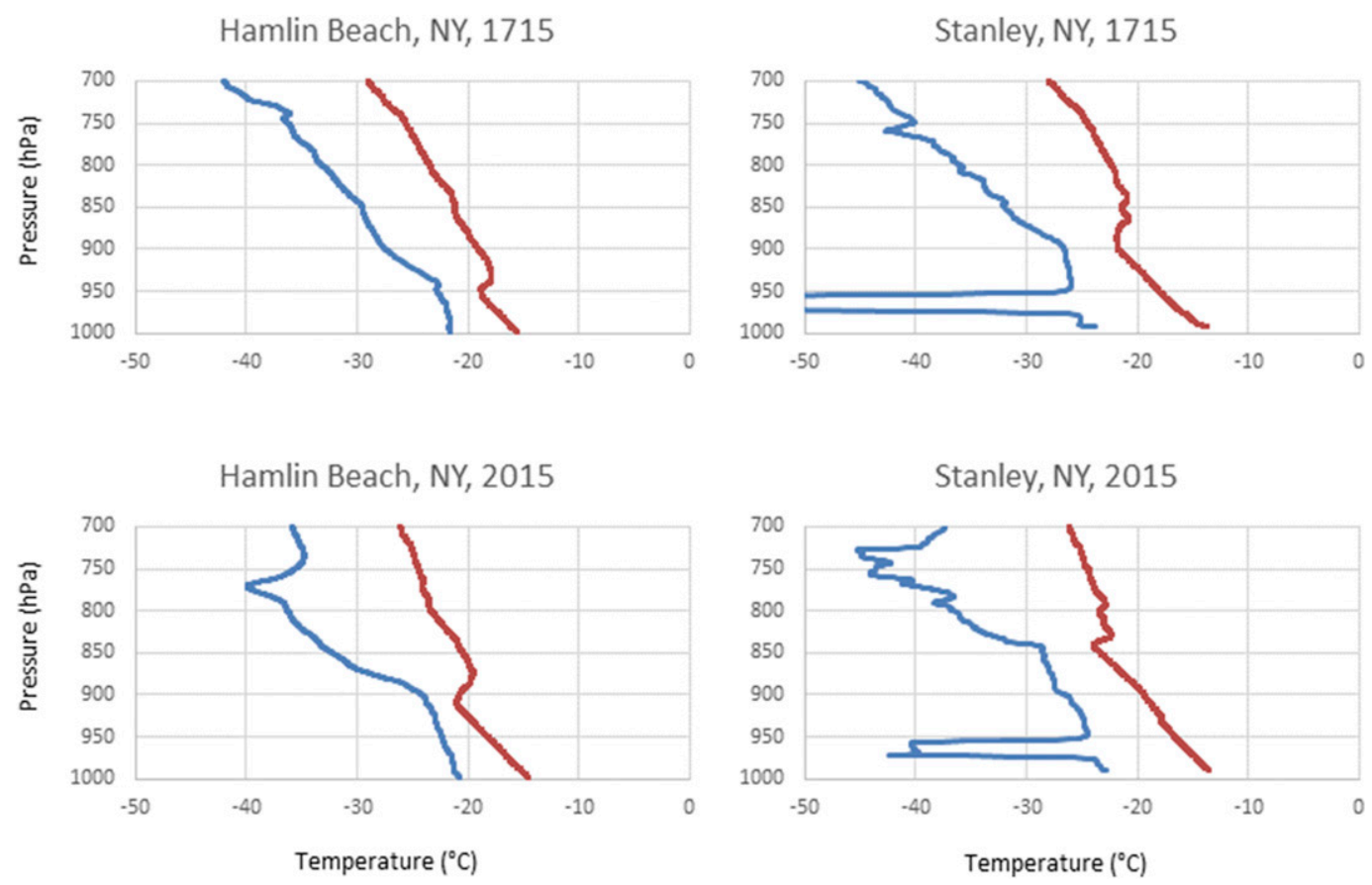

FIG. 4. Linear plot of temperature and dewpoint vertical profiles taken at (left) Hamlin Beach and (right) Stanley, at (top) 1715 and (bottom) 2015 UTC 28 Jan 2014. Red lines represent temperatures, and blue lines represent dewpoint temperatures.

soundings taken at Stanley, southeast of the Lake Erie plume, and at Hamlin Beach, near the Lake Ontario shoreline, within the plume. Temperature profiles are indicative of a near-neutral-stability PBL up to a capping inversion at both times and locations. The Hamlin Beach sounding indicated greater moisture content and relative humidity within the plume, as compared with lower moisture content outside the plume at Stanley (particularly a very dry layer near $960 \mathrm{hPa}$ ). However, the PBL top at Stanley appears to be more than $50 \mathrm{hPa}$ higher than that at Hamlin Beach. Implications of this will be discussed in more detail below.

\section{b. Shoreline transitional PBL (STPBL)}

OWLeS observations taken on 28 January 2014 offer the unique opportunity to document changes in the PBL as the air moved from land to over Lake Ontario. Perhaps the most apparent feature is the relative lack of clouds between the western and southern shores of Lake Ontario and the initiation of lake-effect clouds. The satellite image in Fig. 3 shows that the low-level clouds originating from over Lake Erie were not evident over and north of the Lake Ontario shoreline. However, exactly where the UPBL clouds from Lake Erie dissipated is difficult to discern due to the snow-covered ground below them. Forward-oriented photographic images taken from the UWKA along flight stack B provide some insight into the evolution of the clouds in the region of the STPBL. Forward-looking photographs during all three of the stack B passes show decreased cloudiness near the coast, relative to over the land area to the WSW and to the ENE over Lake Ontario. Figure 5 shows an example image taken as the aircraft was flying at an altitude of approximately $800 \mathrm{~m}$ toward

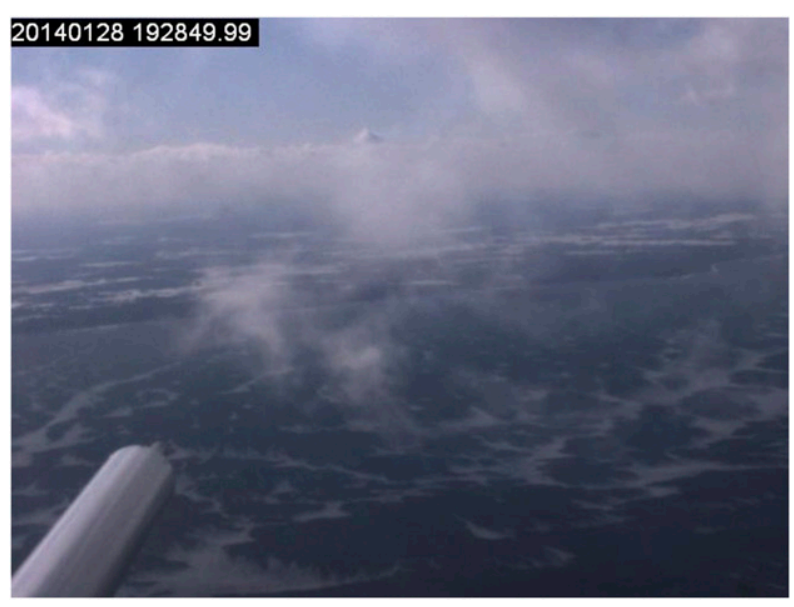

FIG. 5. Photograph taken from the UWKA forward-looking video camera at approximately 1929 UTC 28 Jan 2014. This photograph was taken along track $\mathrm{B}$, approximately due north of Round Pond (Fig. 1). 
the west. A final wisp of lake-effect cloud within the OPBL over Lake Ontario is in the foreground, followed by clear skies above the shoreline region just ahead. Clouds within the UPBL are visible in the distance over New York State.

Radiosonde soundings shown in Fig. 4 provide additional insight into the reason for this cloud-free STPBL. Even though the PBL observed near the shoreline (Hamlin Beach) was more moist than outside the plume of air modified by Lake Erie (Stanley), the PBL depth (estimated by the base of the inversion) was notably lower than that at Stanley at both 1715 and 2015 UTC. For comparison, the mixed-layer depth was compared to operational and OWLeS project soundings surrounding Lake Ontario (Fig. 6). While all sites showed the increase in depth of the mixed layer by approximately 300-600 $\mathrm{m}$ over the 3-h time period, the Hamlin Beach sounding maintained the lowest mixed-layer depth at both observation times. It is hypothesized that the lower mixed-layer depth at Hamlin Beach is in response to a mesoscale downdraft associated with divergence of surface winds moving from land to the smoother lake surface.

Flight stack B provides a unique opportunity to examine details of the spatial and temporal evolution of the STPBL as the air crossed from northwestern New York State to over Lake Ontario. In situ observations from two of the flight legs, B3 and B2, were well into the stable air above the boundary layer, as evidenced by the higher potential temperatures (averages of 267.4 and $263.9 \mathrm{~K}$ for legs B3 and B2, respectively, as compared with a $259.2-\mathrm{K}$ average for leg B1). In addition, relative humidities were much lower $(19 \%-25 \%)$ in legs B3 and B2 than in leg B1 (about 58\% average), and there was a lack of clouds and few snow particles [average twodimensional cloud particle probe (2D-C) concentrations of 0.12 and $0.16 \mathrm{~L}^{-1}$ for legs $\mathrm{B} 3$ and $\mathrm{B} 2$, respectively, as compared with $1.44 \mathrm{~L}^{-1}$ for leg B1]. Observations near the top of the STPBL taken during flight leg B1 did provide interesting information regarding atmospheric processes near the shore. B1 had an average pressure of $920 \mathrm{hPa}$ (Table 1), slightly below the boundary layer top measured at Hamlin Beach about $45 \mathrm{~min}$ later (2015 UTC; Fig. 4). Figure 7 shows several atmospheric state variables measured by the UWKA as it flew over the coastal region. From west to east before reaching the shore, relative humidity and potential temperature changed modestly, decreasing by about $5 \%$ and increasing by about $0.5 \mathrm{~K}$ on average, respectively.

Near the transition zone between ice cover and open water on Lake Ontario, relative humidity sharply decreased by about $25 \%$ while potential temperature increased by nearly $2 \mathrm{~K}$, suggesting an intrusion of
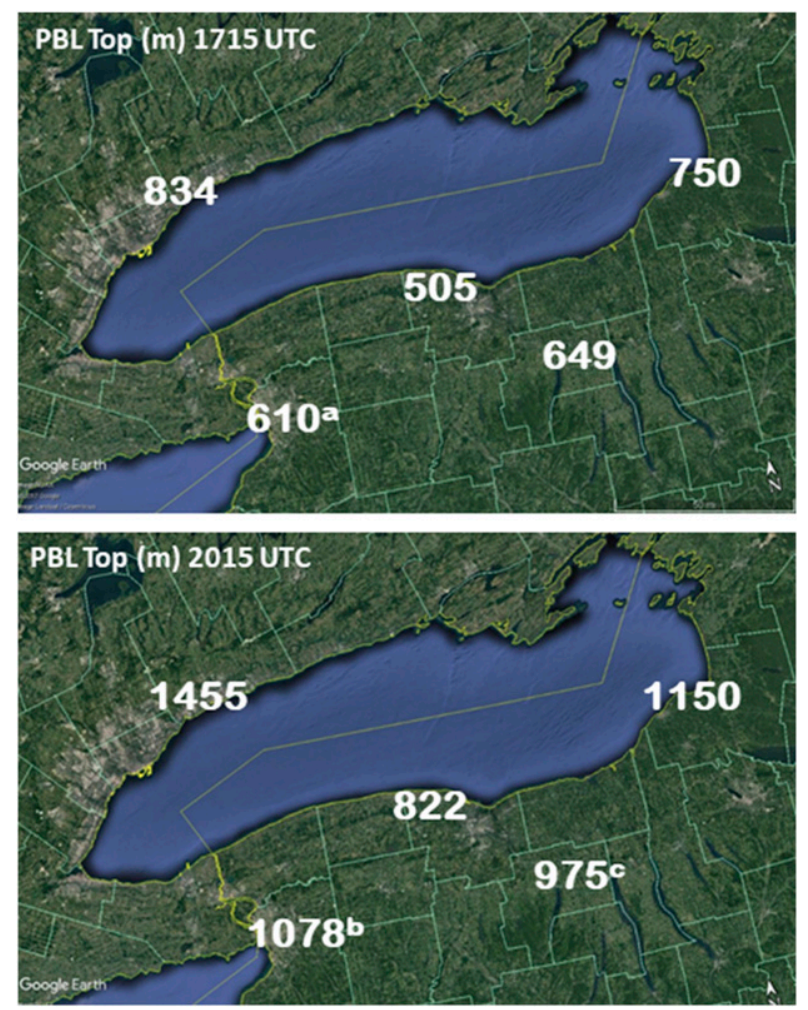

FIG. 6. Approximate height of the top of the PBL observed at OWLeS operations sites at (top) 1715 and (bottom) 2015 UTC 28 Jan 2014. The KBUF observations near the eastern shore of Lake Erie that are labeled with "a" and "b" were taken from the closest operational soundings reported: 1200 UTC 28 Jan and 0000 UTC 29 Jan 2014, respectively. The value that is labeled with "c" is highly uncertain because it is due to a subtle change in the temperature lapse rate; a much higher inversion height is also evident in the sounding.

above-STPBL air associated with the downdraft with magnitude from -2 to $-3 \mathrm{~m} \mathrm{~s}^{-1}$. Potential temperature and relative humidity within the area of strongest downdraft suggest that the intrusion originated at least $300 \mathrm{~m}$ above leg B1, as based on average conditions measured above. The horizontal size of the intrusion along the UWKA flight leg was $3-4 \mathrm{~km}$ on the basis of vertical motions and about $8 \mathrm{~km}$ on the basis of potential temperature and relative humidity variations. This location of the warm, dry intrusion is consistent with the cloudless area discussed earlier, except it is much smaller. Photographs from all three flight legs in stack B indicated $9-26 \mathrm{~km}$ of cloudless conditions, more than 3 times the intrusion size. Note that at least one other smaller, less distinct intrusion of dry, warm air from above flight leg B1 was seen over land to the west (e.g., 1936 UTC).

Farther to the east over open water, the UWKA briefly entered PBL air exhibiting higher relative humidity and 


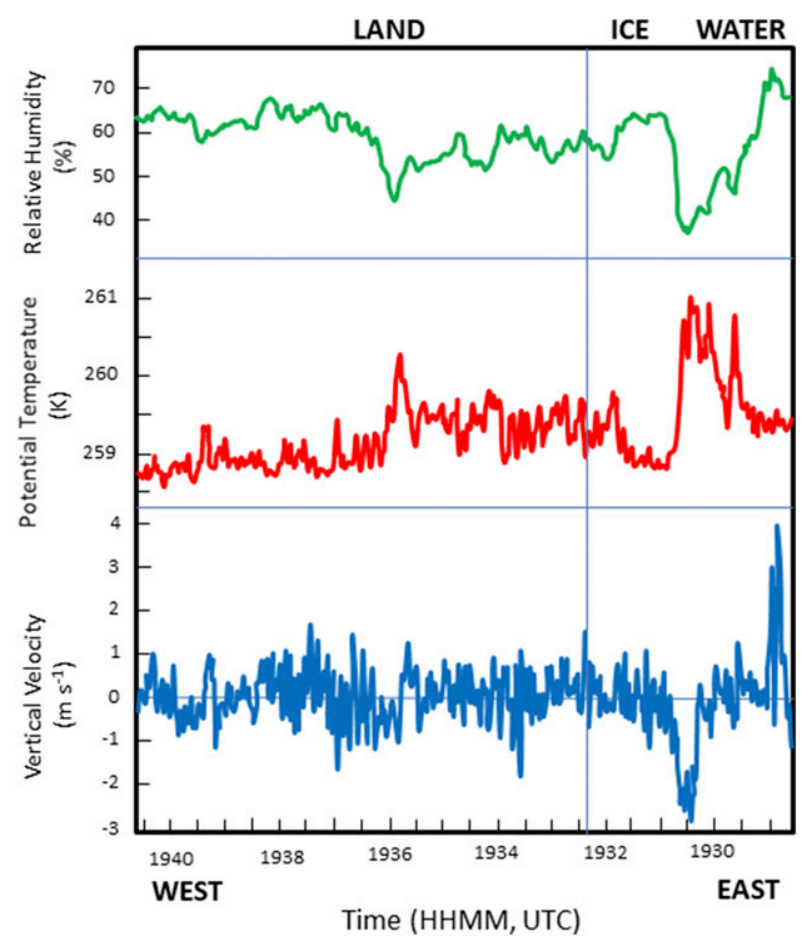

FIG. 7. The 1-Hz in situ observations of (top) relative humidity, (middle) potential temperature, and (bottom) vertical velocity taken along flight leg B1. The data are shown from west to east over areas of land (UPBL), ice, and open water (OPBL), as indicated. The vertical blue line is the shoreline.

stronger updrafts of up to $4 \mathrm{~m} \mathrm{~s}^{-1}$. In addition, the potential temperature was slightly higher than to the west of the dry, warm air intrusion.

WCR observations taken above and below the UWKA in stack B (Fig. 8) provide additional information on the structure of the STPBL precipitation. Overall, reflectivity decreased from the UPBL (left) to near the Lake Ontario shore and to the east, with some temporal variation within that zone. This corresponds reasonably well to the clear-air region estimated from photographic imagery from the three flight legs, but again is a much larger area than estimated from in situ observations in leg B1. This lower-reflectivity feature was visible over the entire 2 -h time period. It is interesting that the reflectivity regions observed by the WCR east of the cloud-free zone extended several hundred meters higher than they did over land to the west.

Note that the decreased reflectivity observed by the WCR near the shoreline does not indicate a lack of snow particles. The $2 \mathrm{D}-\mathrm{C}$ probe indicated low concentrations of snow particles in patches across the entire flight leg (average concentrations of approximately $1 \mathrm{~L}^{-1}$ across the low-reflectivity region during flight leg B1; see Fig. 8, bottom panel). WCL observations (Fig. 9) also showed patches of somewhat higher backscatter coefficient near the approximate height of the PBL top. This suggests that as the glaciated clouds dissipated in this lowreflectivity zone, low concentrations of snow particles likely traversed the STPBL, especially near its top.

Doppler vertical winds from the WCR were examined to better understand relationships between the larger region of apparent subsidence and the kilometer-scale eddies inferred from UWKA in situ observations. As will be seen, these eddies are on the same size and velocity scales as "updraft and downdraft cores" identified by Braham and Kristovich (1996). We will adopt their nomenclature here.

Figure 10 shows the Doppler vertical motions observed by the WCR concurrently with the reflectivity features shown in Fig. 8. Vertical motions in cores were generally observed to be less than $\pm 5 \mathrm{~m} \mathrm{~s}^{-1}$ in magnitude, consistent with in situ observations from the UWKA. Areas of small-scale updraft and downdraft cores were identified through examination of columns of measured vertical velocities recorded at $1-\mathrm{Hz}$ intervals. For each column, vertical velocities were examined at 100-m intervals from the surface (i.e., up to 10 observations within a 1000-m-deep reflectivity layer). To account for some layers with no observed reflectivity and variations in velocities observed within the turbulent PBL, the column was classified as "potential updraft" ("potential downdraft") if at least $60 \%$ of the observations were positive (negative). If at least two consecutive columns were classified the same, the columns were defined as an updraft or downdraft, as appropriate. Updraft cores were generally $500 \mathrm{~m}$ or less horizontally, but some were nearly $2 \mathrm{~km}$ across (yellow dashes in Fig. 10). Downdraft cores (not identified in Fig. 10) tended to be somewhat larger and weaker, which is common for convective boundary layers. It is not possible to determine from these observations whether convective eddies in the STPBL were different from those in the OPBL because of a lack of scatterers (snow) for the WCR to observe.

Ideally, to understand the evolution of cores throughout this region, individual updraft and downdraft cores would be monitored as they moved throughout the STPBL. Since these data do not allow for that analysis, locations of cores were compared between the three flight legs in stack B; updraft cores are illustrated in Fig. 10 by yellow-colored bars. While the region of apparent subsidence remained within about $10-16 \mathrm{~km}$ of the coastline, no consistency was found for the locations of the cores. This suggests that the small-scale updraft and downdraft cores evolve much more rapidly as they move through the mesoscale subsidence region in the STPBL and toward the OPBL. 


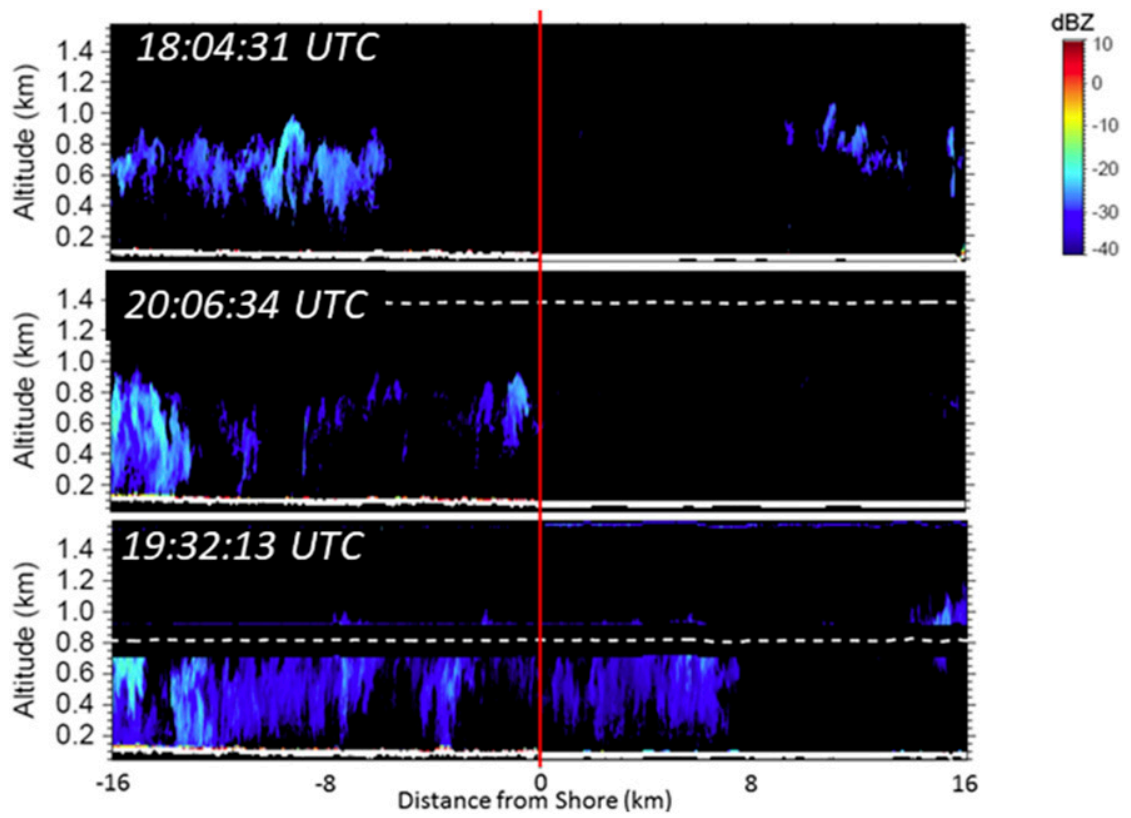

FIG. 8. Effective reflectivity factor (dBZ) observed by the WCR aboard the UWKA at three times. The vertical scans are shown. Each flight leg crossed the shoreline along track B in Fig. 1. Approximate heights of the flight legs were at (top) 1.9-, (middle) 1.4-, and (bottom) $0.8-\mathrm{km}$ altitude above the surface, as shown by the white dashed lines in the bottom two panels. Approximate times of shore crossing were 1804:31, 2006:34, and 1932:13 UTC.

\section{c. Lake Ontario lake-effect PBL (OPBL)}

Operational and OWLeS observations are able to provide insight into the influence of the plume of modified air from Lake Erie (cloudy plume in the UPBL) on the evolution of the OPBL over Lake Ontario. Figure 3 highlights the spatial variations in lake-effect clouds over Lake Ontario and their relationship with lake-effect clouds in the UPBL and STPBL. A band of apparently deeper lake-effect clouds over eastern Lake Ontario (thick blue line in Fig. 3) has a similar orientation and is almost directly downwind of the southeastern edge of the Lake Erie plume in the UPBL. To determine whether these two features are spatially connected, the southernmost locations of lake-effect clouds (or much thicker clouds), as seen in UWKA forward-looking photographs, along flight legs A, C, and E are identified in Fig. 3. The UWKA cloud edge observations align very well with the southeastern edge of the Lake Erie plume and the edge of thick lake-effect clouds visible over southeastern Lake Ontario.

Note that at the time of the MODIS image in Fig. 3 an area of more scattered clouds (typically associated with an area of shallower lake-effect PBL) was evident north of flight stacks $\mathrm{C}$ and $\mathrm{E}$. Animations of GOES imagery showed that this feature propagated with the wind from southwest to northeast, while the overall Lake Erie plume structure remained nearly stationary. Since this

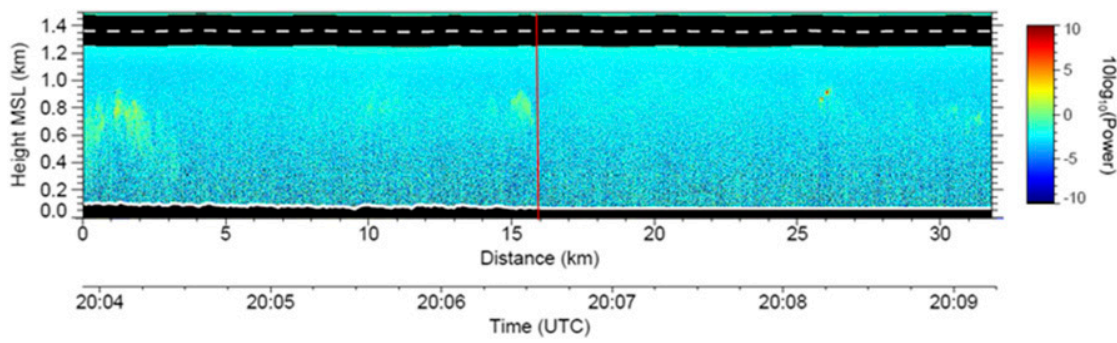

FIG. 9. As in the middle panel of Fig. 8, but for backscatter coefficient observed by the WCL. The approximate time that the aircraft passed over the shore is shown with the vertical red line near 2006:34 UTC. 


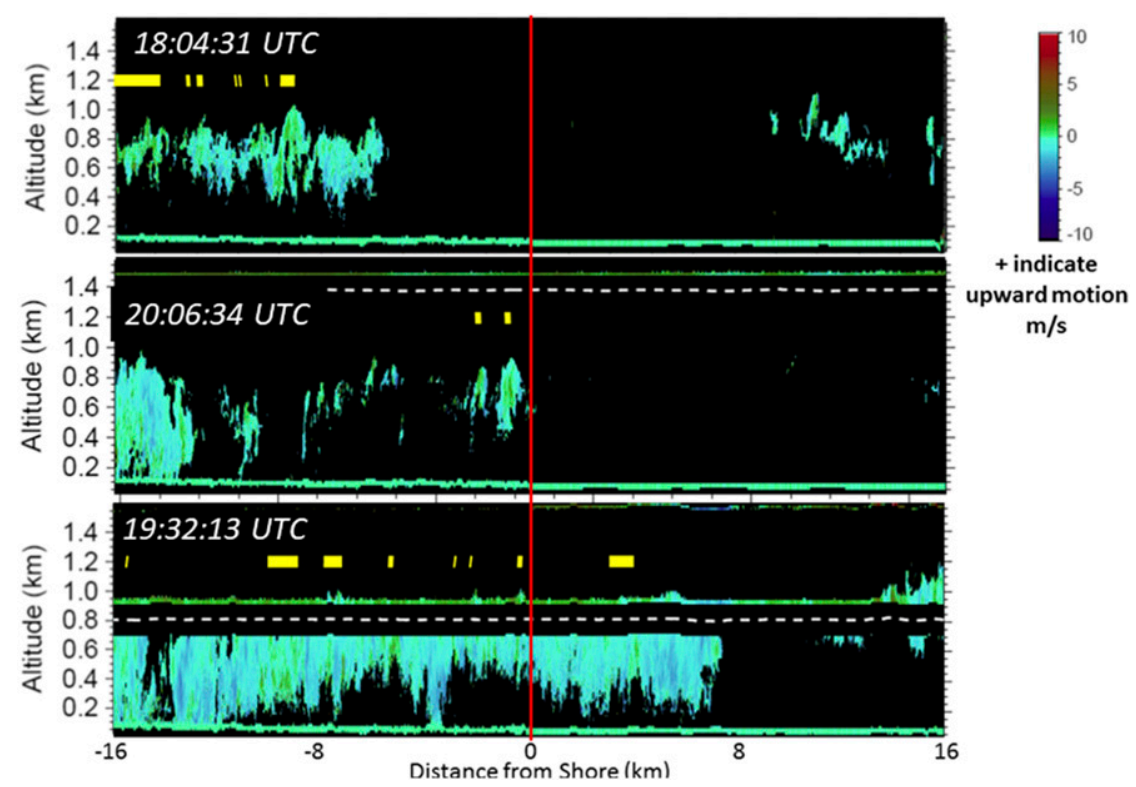

FIG. 10. As in Fig. 8, but for vertical velocity observations. Locations of updraft "cores" are shown by thick yellow line segments.

feature was transient and did not appear to influence the overall interactions between the Lake Erie plume and the lake-effect system over Lake Ontario, no further analyses were conducted on this feature.

Figure 3 also shows the along-wind fetch distance from the southern and western coasts of Lake Ontario to the location where clouds became evident in the satellite imagery. Within the Lake Erie plume, lake-effect clouds developed within the $10-20-\mathrm{km}$ fetch from the coastline (red arrows). Northwest and southeast of the Lake Erie plume, clouds developed within the OPBL at approximately 2 times the distance (orange arrows) that they did within the plume. This result suggests that, despite the apparent rapid changes in the STPBL, the Lake Erie plume still influenced lake-effect convection farther downwind to the northeast.

Observations taken during UWKA flight legs $\mathrm{E}$ and $\mathrm{G}$ provide additional information on how the OPBL was influenced by the Lake Erie plume. The cloud pattern shown in Fig. 3 suggests that these flight legs may observe differing atmospheric conditions in three regions: 1) over land, with no lake influences, 2) over Lake Ontario to the south of the Lake Erie plume, with singlelake influence on the OPBL, and 3) within the Lake Erie plume, with influences from Lakes Erie and Ontario. These three regions can be seen in snowfall-rate changes apparent in WCR observations. Figure 11 (top panel) gives the reflectivity profiles measured by the WCR and backscatter power profiles measured by the WCL (bottom panel) along flight leg G1 and the three regions determined as in Fig. 1. Distinct regions of differing snowfall rates approximately correspond to the three regions, with the heaviest snow in the Lake Erie and Lake Ontario combined OPBL region. For illustration, maximum snowfall rates in the combined OPBL region would be at least an order of magnitude greater than in the Lake Ontario-only region, using effective reflectivity-factor-snowfall-rate relationships for $95-\mathrm{GHz}$ radars provided by Kulie and Bennartz (2009) and Matrosov (2007). Similar patterns were seen in the other flight legs along stacks $E$ and $G$ (not shown). In situ observations of potential temperature, moisture content, and precipitation particles showed similar patterns (not shown), but variability along the flight tracks often obscured the distinct changes seen in WCR observations at the boundaries of these three regions.

Interestingly, WCL observations suggest distinctly different cloud characteristics between these three regions (Fig. 11, bottom panel). In the Lake Ontarioonly region, high backscatter indicates the presence of liquid water clouds near the OPBL top. The largely supercooled liquid clouds caused rapid extinction of the lidar beam, thus precluding the WCL from observing below the top of the clouds. However, the WCL was able to penetrate farther into the OPBL clouds in the Lake Erie plume region, suggesting lesser concentrations of liquid droplets in locations of more ice. A similar pattern was observed by this instrument in lake-effect clouds over the New York Finger Lakes (Bergmaier and Geerts 2016). 


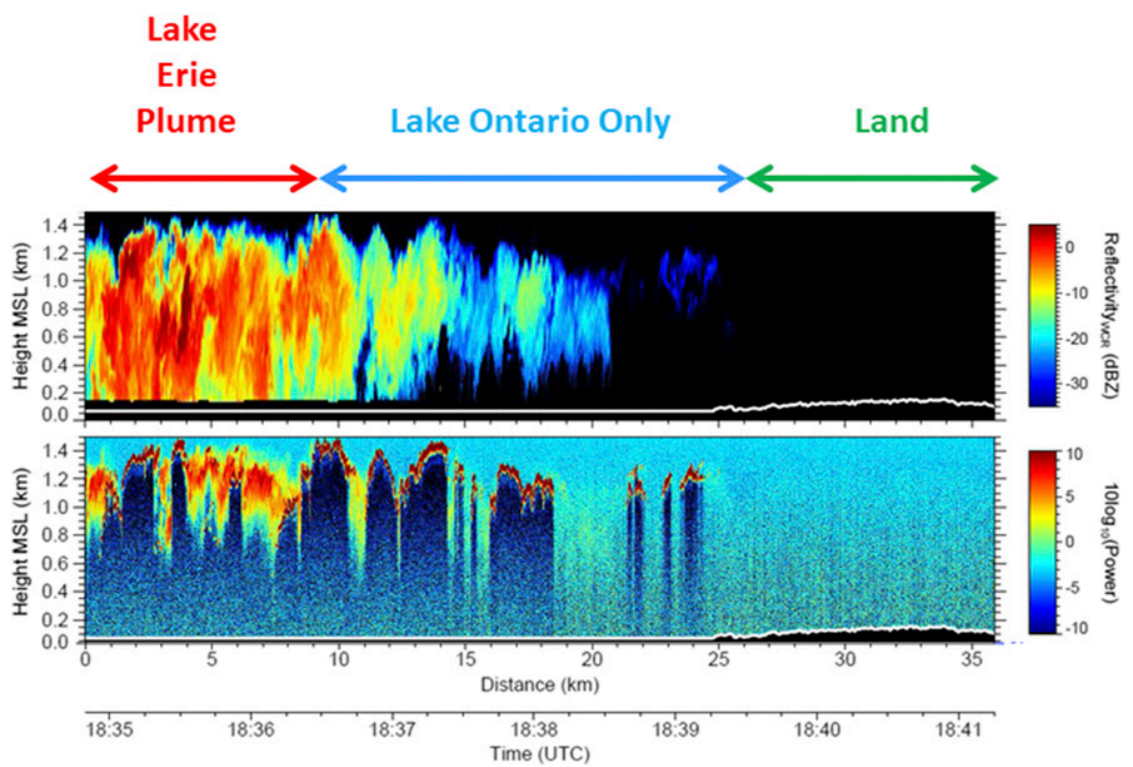

FIG. 11. (top) Effective reflectivity factor observed by the WCR aboard the UWKA along flight leg G3. (bottom) Lidar backscatter coefficient observed by the WCL along flight leg G3. The locations of the Lake Erie plume, the region where there was lake-effect only from Lake Ontario, and land areas were approximated by detailed plotting of the aircraft positions on the MODIS image in Fig. 3.

To estimate the influence of Lake Erie on the OPBL dynamic structure, turbulence intensity was calculated from WCR Doppler vertical velocity measurements within the same regions illustrated in Fig. 11. Figure 12 shows profiles of turbulence intensity (that are based on vertical motions only), averaged over 1-min time periods in flight leg G1. Overall, the TKE per unit mass profiles were similar to those observed in previous convective boundary layer studies (e.g., Stull 1988), with increasing values to a height within the PBL and then decreasing values to the PBL top. The values of TKE, however, exhibited considerable change from southeast to northwest along the flight leg. Maximum TKE magnitudes within the OPBL increased from approximately 2.5 to $3.3 \mathrm{~m}^{2} \mathrm{~s}^{-1}$. A slight tendency for increasing height of the maximum TKE toward the northwest part of the flight leg could be inferred, but the increase was not consistent. While these results are very interesting and are worthy of additional study, we have found that minor changes in UWKA roll angle can produce large changes in estimated turbulence intensity, and therefore some uncertainty remains in these findings.

\section{Discussion}

This study examined data collected during the OWLeS field experiment (Kristovich et al. 2017) to better understand the processes by which an upwind lake (Lake Erie in this case) influences lake-effect convection over a downwind lake (Lake Ontario). OWLeS provided the first detailed observations of the evolution of the PBL from between the two lakes (upwind; UPBL), as the air crosses the shoreline (shoreline transition; STPBL), and over the downwind lake (Lake Ontario; OPBL).

It was shown that in this case, Lake Erie modified cold, dry air crossing over it from southwest to northeast. This plume of modified air crossed portions of northwestern New York State, maintaining a near-neutral (well mixed) PBL until reaching the southwestern shore of Lake Ontario. It is interesting that the observed neutral stability is in opposition to commonly assumed rapid stable-layer development once the air from Lake Erie moved over land (e.g., Rose 2000; Tripoli 2005). Alternatively, observational soundings over land downwind from a lake producing lake-effect snow events frequently show no inland stable layer (e.g., Chang and Braham 1991; Kristovich et al. 1999; 2003), presumably because of mixing within the lower boundary layer and lack of radiation loss from the surface under cloudy skies. This illustrates that a stable layer over land should not be assumed in these cases.

The plume of modified air had a distinct influence on the structure and intensity of lake-effect convection over Lake Ontario. In particular, lake-effect cloudiness over 


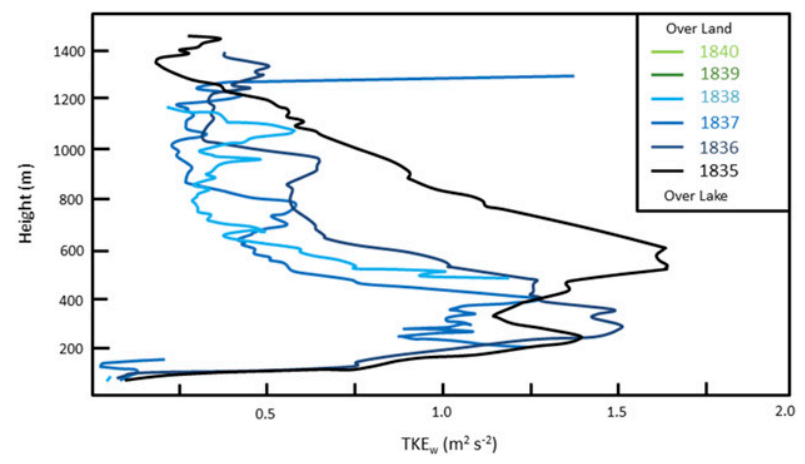

FIG. 12. Profiles of TKE per unit mass calculated from vertical velocities from the WCR along flight leg G3. Each line denotes 1-min average values starting at the times indicated in the legend. The UWKA flight leg was oriented toward the SSE starting over Lake Ontario at 1835 UTC and ending over land after 1840 UTC. A lack of scatterers prevented profiles of TKE from being observed over land.

Lake Ontario was thicker within the Lake Erie plume of modified air, snowfall intensity was increased (as evidenced by radar reflectivity observations), TKE appeared to be higher in magnitude, and the PBL was deeper. Several processes may be involved in the interactions between the UPBL and OPBL:

1) Increased atmospheric humidity would be expected to lower the cloud-base height, consistent with the more rapid development of clouds over Lake Ontario within the Lake Erie plume than outside the plume (Fig. 3).

2) Convective eddies within the UPBL observed by WCR Doppler wind measurements and in situ observations by the UWKA appeared to continue across the shore and strengthen in the OPBL. This is consistent with Byrd et al. (1991), who argued that such vertical motions over land upwind would be augmented in lake-effect convection over a lake. Similar augmentation was found for lake-effect situations by Rose (2000), Deacu et al. (2012), and Wright et al. (2013). Such intensifications of convective vertical motions have been found for other cases in which air moved over a relatively warm surface. Nonlocal entrainment would be expected to increase as a result of nonlocal surface thermal forcing (i.e., intensified vertical motions enhancing mixing at the PBL top; e.g., Stull 1988; Young and Sikora 2003; etc.), consistent with the observed deepening of the OPBL.

3) In principle, a gravity wave train could be generated by surface changes upwind of the shore (such as over Lake Erie) and provide for an area of downward motion over the shoreline. However, the lack of periodic changes in cloud features on either side of the STPBL suggests this did not occur in this case.

4) A deeper UPBL mixed layer within the Lake Erie plume would allow surface-based convection over Lake Ontario to extend up to a higher capping inversion. However, observations here indicate that a decrease in the depth of the STPBL may limit the influences of a greater UPBL depth, as discussed below.

5) Snow particles from within the UPBL were observed in low concentrations by the WCL and particle probes aboard the UWKA across the STPBL. These ice particles could increase the rate of glaciation of lake-effect clouds once they form. Such ice particles could not have been a reason that liquid clouds developed at shorter fetches over Lake Ontario within the Lake Erie plume, as compared to outside the plume, due to the cold air temperatures and much lower concentrations of ice particles than liquid cloud particles. Subsequent to cloud formation in the OPBL, however, these ice particles could have contributed to producing the observed heavier snowfall and a somewhat deeper PBL due to added latent heat release (as observed in Schroeder et al. 2006). Further observational and numerical work is needed to quantify the relative influences of ice particles from upwind lake-effect systems (or from surface blowing snow in some cases) on snowfall rates over the downwind shoreline areas.

Perhaps the most striking aspect of this case study is the identification of a quasi-stationary mesoscale downdraft near the upwind coast of Lake Ontario. This feature was evidenced by a decreased radiosondemeasured PBL depth near the shoreline relative to that measured at surrounding sounding sites. Satellite, photographic images and in situ data from the UWKA, along with WCR reflectivity observations, showed that this feature remained in the vicinity of the shore for multiple hours during OWLeS operations.

Detailed observations of such a STPBL feature have not been reported in the lake-effect literature in cases of multiple-lake lake-effect events. Indeed, most recent studies focusing on lake-effect convection over a single lake also did not discuss this feature. Early analytical and simplified numerical modeling efforts predicted that the PBL depth would reach a minimum at the upwind shoreline (e.g., Hsu 1987; Sousounis and Shirer 1992; Rose 2000). Yuen and Young (1986) found that the subsequent growth of the overwater (OPBL in this case) may not always reach the depth of the UPBL. While most numerical modeling studies in more recent years provide evidence of an increase in nearsurface horizontal wind speeds (e.g., see figures in 


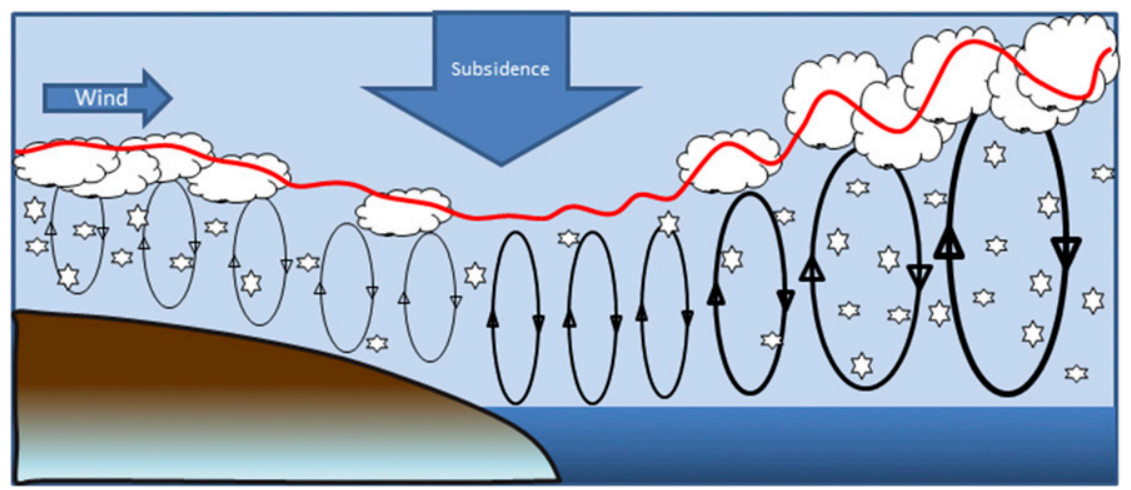

FIG. 13. Conceptual model of turbulent eddies as they moved from the UPBL at the left of the figure, across the more shallow STPBL, and then to the OPBL at the right of the figure. The red line indicates the approximate top of the PBL as well as its relative variability. The schematic is stretched vertically to make the changes more evident. Relative thickness of the turbulent eddies (ovals with arrows) indicates relative magnitude of the vertical motions.

Hjelmfelt and Braham 1983; Hjelmfelt 1990; Steenburgh and Onton 2001; Onton and Steenburgh 2001), only a few provided information on the locations and areal extent of surface divergence or resulting mesoscale downdrafts near the shoreline (Steenburgh and Campbell 2017; Tripoli 2005).

It might be expected that a decrease in PBL depth near the shoreline could limit its subsequent growth over the lake, but little is known about this process. For example, the few modeling studies indicating a decrease in PBL depth near the upwind shore in lake-effect situations did not discuss impacts on the overlake PBL evolution (Rose 2000; Tripoli 2005; Conrick et al. 2015). Similarly, observational studies in the literature generally have limited data near the upwind shore and thus show either no PBL depth decrease or infer a more shallow boundary layer near the upwind shore through physical principles (Lenschow 1973; Chang and Braham 1991; Kristovich et al. 2003; Schroeder et al. 2006). An exception is Wright et al. (2013), who showed a decrease in PBL depth by about a third $(800 \mathrm{~m})$ as it approached the Lake Erie shore. They discussed its possible origin in near-surface divergence, but interpretation of this feature was complicated by a nearby band of convection along the shore in their case. Clearly, a consistent understanding of the evolution of the STPBL is not yet available.

Given the significant changes observed in the STPBL, it is evident that the plume of air modified by Lake Erie continued to have an important influence over Lake Ontario. Figure 13 provides a conceptual model of how the PBL and convective air motions within it evolved as the air moved across the coastal region. Updraft and downdraft eddies evident in the UPBL appear to have been intensified in the OPBL. These, in turn, would have led to increased PBL top height, stronger local vertical motions, and more rapid entrainment, as observed by the UWKA in flight leg B1.

Unfortunately, inadequate snow particle concentrations within the coastal area precluded determination of how the structure of the convective eddies changed across the STPBL using the WCR. The WCL observed small concentrations of ice particles in some locations across the STPBL, but was not able to observe vertical motion structures throughout its depth. It is suggested that future field efforts take in situ and remote sensing observations, particularly with sensors capable of observing clear-air air motions (such as Doppler lidars, flux towers, etc.), in the STPBL to quantify how the convective eddies and PBL interacted in this area of rapid changes in surface conditions. This effort would provide a dataset for evaluation and further improvement of simulations of the lake-effect PBL and its evolution under varying environmental conditions.

\section{Conclusions}

Unique observations from the OWLeS field campaign taken on 28 January 2014 documented the evolution of the PBL between two lake-effect snow-producing lakes (Erie and Ontario). It was found that the convective boundary layer with clouds and snow that developed over Lake Erie maintained this structure until reaching near the southwestern shore of Lake Ontario and did not develop a surface-based stable layer over land as is commonly assumed. Convective plumes were evident in WCR Doppler observations traversing the boundary layer over land.

Near the shoreline of Lake Ontario, the boundary layer became substantially more shallow, presumably in 
response to surface wind divergence as the air moved from the relatively rough land surface of northwestern New York State to over Lake Ontario. In situ observations from the UWKA near the top of the boundary layer indicated that the presence of areas of relatively strong downdrafts was accompanied by air drawn down from the dry, stable air above the PBL. This mesoscale area of shallow PBL depth remained quasi-stationary for nearly $3 \mathrm{~h}$ during sounding and UWKA operations. While regions of cloudless skies are common near the upwind shores of the Great Lakes during lake-effect situations, little is known about the factors that control the intensity and size of the mesoscale subsidence region, the response of the PBL vertical structure, and the characteristics of convective eddies crossing this surface boundary.

Despite the abrupt changes in the PBL near the shoreline, the plume of modified air from Lake Erie had a notable effect on the lake-effect system that developed over Lake Ontario. Observations indicate that lake-effect clouds redeveloped more rapidly, the PBL grew deeper, and precipitation and turbulent kinetic energy were greater within the plume than in areas over Lake Ontario that were outside the plume.

The impact of the rapid changes in the PBL near the upwind shore of a lake on the future evolution of the lake-effect system is not well understood. Factors determining the magnitude of the nearshore divergence and decreased PBL depth, as well as the subsequent evolution of the PBL over a lake, have not been explored in the literature. This case was a late-season event in which Lake Erie was largely ice covered. It appears feasible that earlier-season events with less ice cover over upwind lakes could have much more influence on the PBL over downwind lakes. Further research is recommended to investigate environmental and surface factors influencing the development and evolution of this phenomenon and its ultimate influence on the lake-effect system that develops downwind.

Acknowledgments. The authors thank members of the Mesoscale/Boundary Layer Meteorology Group at the ISWS, Prairie Research Institute, past and present, for their help and input on the OWLeS field project. Thanks are given to principal investigators, scientists, students, volunteers, and instrument-platform staff and managers for their exceptional professionalism and efforts. OWLeS was funded by the National Science Foundation, and research carried out by these authors was funded by Physical and Dynamic Meteorology Program Grants NSF AGS 12-59004 (Illinois) and AGS 12-58856 (Wyoming). Much of the WCR and WCL software was initially developed by Samuel Haimov. David King reviewed this manuscript and gave valuable insights through initial analyses. Comments from three anonymous reviewers and the editor (Qi Hu) led to a greatly improved paper. Olivia Kellner developed the original base map for Fig. 1. Opinions expressed are those of the authors and are not necessarily those of the authors' affiliated institutions or the National Science Foundation.

\section{REFERENCES}

Ackerman, S., A. Heidinger, M. Foster, and B. Maddux, 2013: Satellite regional cloud climatology over the Great Lakes. Remote Sens., 5, 6223-6240, https://doi.org/10.3390/rs5126223.

Agee, E. M., and S. R. Gilbert, 1989: An aircraft investigation of mesoscale convection over Lake Michigan during the 10 January 1984 cold air outbreak. J. Atmos. Sci., 46, 1877-1897, https://doi.org/10.1175/1520-0469(1989)046<1877: AAIOMC $>2.0 . \mathrm{CO} ; 2$.

Ballentine, R. J., A. J. Stamm, E. E. Chermack, G. P. Byrd, and D. Schleede, 1998: Mesoscale model simulation of the 4-5 January lake-effect snowstorm. Wea. Forecasting, 13, 893-920, https://doi.org/10.1175/1520-0434(1998)013<0893: MMSOTJ $>2.0 . \mathrm{CO} ; 2$.

Bergmaier, P. T., and B. Geerts, 2016: Airborne radar observations of lake-effect snowbands over the New York Finger Lakes. Mon. Wea. Rev., 144, 3895-3914, https://doi.org/10.1175/ MWR-D-16-0103.1.

Braham, R. R., Jr., and D. A. R. Kristovich, 1996: On calculating the buoyancy of cores in a convective boundary layer. J. Atmos. Sci., 53, 654-658, https://doi.org/10.1175/15200469(1996)053<0654:OCTBOC>2.0.CO;2.

Byrd, G. P., R. A. Anstett, J. E. Heim, and D. M. Usinski, 1991: Mobile sounding observations of lake-effect snowbands in western and central New York. Mon. Wea. Rev., 119, 2323-2332, https://doi.org/10.1175/1520-0493(1991)119<2323: MSOOLE $>2.0 . \mathrm{CO} ; 2$.

Chang, S. S., and R. R. Braham Jr., 1991: Observational study of a convective internal boundary layer of Lake Michigan. J. Atmos. Sci., 48, 2265-2279, https://doi.org/10.1175/ 1520-0469(1991)048<2265:OSOACI > 2.0.CO;2.

Conrick, R., H. D. Reeves, and S. Zhong, 2015: The dependence of QPF on the choice of boundary- and surface-layer parameterization for a lake-effect snowstorm. J. Appl. Meteor. Climatol., 54, 1177-1190, https://doi.org/10.1175/JAMC-D14-0291.1.

Cordeira, J. M., and N. F. Laird, 2008: The influence of ice cover on two lake-effect snow events over Lake Erie. Mon. Wea. Rev., 136, 2747-2763, https://doi.org/10.1175/2007MWR2310.1.

Deacu, D., V. Fortin, E. Klyszejko, C. Spence, and P. D. Blanken, 2012: Predicting the net basin supply to the Great Lakes with a hydrometeorological model. J. Hydrometeor., 13, 1739-1759, https://doi.org/10.1175/JHM-D-11-0151.1.

Ellis, A. W., and D. J. Leathers, 1996: A synoptic climatological approach to the analysis of lake-effect snowfall: Potential forecasting applications. Wea. Forecasting, 11, 216-229, https:// doi.org/10.1175/1520-0434(1996)011<0216:ASCATT>2.0.CO;2.

Gerbush, M. R., D. A. Kristovich, and N. F. Laird, 2008: Mesoscale boundary layer and heat flux variations over pack icecovered Lake Erie. J. Appl. Meteor. Climatol., 47, 668-682, https://doi.org/10.1175/2007JAMC1479.1. 
GLERL, 2017: Digital ice chart for 28 January 2014. Great Lakes Environmental Research Laboratory, accessed 15 December 2017, https://www.glerl.noaa.gov/data/ice/atlas/ glicd/jpgs/2014/20140128.jpg.

Hjelmfelt, M. R., 1990: Numerical study of the influence of environmental conditions on lake-effect snowstorms over Lake Michigan. Mon. Wea. Rev., 118, 138-150, https://doi.org/10.1175/ 1520-0493(1990)118<0138:NSOTIO > 2.0.CO;2.

—_, and R. R. Braham, 1983: Numerical simulation of the airflow over Lake Michigan for a major lake-effect snow event. Mon. Wea. Rev., 111, 205-219, https://doi.org/10.1175/15200493(1983)111<0205:NSOTAO > 2.0.CO;2.

Holroyd, E. W., 1971: Lake-effect cloud bands as seen from weather satellites. J. Atmos. Sci., 28, 1165-1170, https://doi.org/ 10.1175/1520-0469(1971)028<1165:LECBAS > 2.0.CO;2.

Hsu, H., 1987: Mesoscale lake-effect snowstorms in the vicinity of Lake Michigan: Linear theory and numerical simulations. J. Atmos. Sci., 44, 1019-1040, https://doi.org/10.1175/ 1520-0469(1987)044<1019:MLESIT>2.0.CO;2.

Kristovich, D. A. R., N. F. Laird, M. R. Hjelmfelt, R. G. Derickson, and K. A. Cooper, 1999: Transitions in boundary layer meso$\gamma$ convective structures: An observational case study. Mon. Wea. Rev., 127, 2895-2909, https://doi.org/10.1175/1520-0493 (1999) $127<2895$ :TIBLMC $>2.0 . C O ; 2$.

$\ldots$, $—$, and 2003: Convective evolution across Lake Michigan during a widespread lake-effect snow event. Mon. Wea. Rev., 131, 643-655, https://doi.org/10.1175/1520-0493 (2003)131<0643:CEALMD>2.0.CO;2.

— , and Coauthors, 2017: The Ontario Winter Lake-effect Systems field campaign: Scientific and educational adventures to further our knowledge and prediction of lake-effect storms. Bull. Amer. Meteor. Soc., 98, 315-332, https://doi.org/10.1175/ BAMS-D-15-00034.1.

Kulie, M. S., and R. Bennartz, 2009: Utilizing spaceborne radars to retrieve dry snowfall. J. Appl. Meteor. Climatol., 48, 25642580, https://doi.org/10.1175/2009JAMC2193.1.

Laird, N. F., R. Sobash, and N. Hodas, 2010: Climatological conditions of lake-effect precipitation events associated with the New York State Finger Lakes. J. Appl. Meteor. Climatol., 49, 1052-1062, https://doi.org/10.1175/2010JAMC2312.1.

Lenschow, D. H., 1973: Two examples of planetary boundary layer modification over the Great Lakes. J. Atmos. Sci., 30, 568-581, https://doi.org/10.1175/1520-0469(1973)030<0568:TEOPBL > 2.0.CO;2.

Mann, G. E., R. B. Wagenmaker, and P. J. Sousounis, 2002: The influence of multiple lake interactions upon lake-effect storms. Mon. Wea. Rev., 130, 1510-1530, https://doi.org/10.1175/ 1520-0493(2002)130<1510:TIOMLI>2.0.CO;2.

Matrosov, S. Y., 2007: Modeling backscatter properties of snowfall at millimeter wavelengths. J. Atmos. Sci., 64, 1727-1736, https://doi.org/10.1175/JAS3904.1.

Niziol, T. A., W. R. Snyder, and J. S. Waldstreicher, 1995: Winter weather forecasting throughout the eastern United States. Part IV: Lake-effect snow. Wea. Forecasting, 10, 61-77, https://doi.org/ 10.1175/1520-0434(1995)010<0061:WWFTTE > 2.0.CO;2.

Onton, D. J., and W. J. Steenburgh, 2001: Diagnostic and sensitivity studies of the 7 December 1998 Great Salt Lake-effect snowstorm. Mon. Wea. Rev., 129, 1318-1338, https://doi.org/ 10.1175/1520-0493(2001)129<1318:DASSOT>2.0.CO;2.

Reeves, H. D., and D. T. Dawson, 2013: The dependence of QPF on the choice of microphysical parameterization for lakeeffect snowstorms. J. Appl. Meteor. Climatol., 52, 363-377, https://doi.org/10.1175/JAMC-D-12-019.1.
Rodriguez, Y., D. A. R. Kristovich, and M. R. Hjelmfelt, 2007: Lake-to-lake cloud bands: Frequencies and locations. Mon. Wea. Rev., 135, 4202-4213, https://doi.org/10.1175/ 2007MWR1960.1.

Rose, B. L., Jr., 2000: The role of upstream lakes in determining downstream severe lake-effect snowstorms. Ph.D. thesis, University of Illinois at Urbana-Champaign, 182 pp., https:// dissexpress.proquest.com/dxweb/results.html?QryTxt $=\& B y=$ Rose $\% 2 \mathrm{C}+$ Bruce + L. $\% 2 \mathrm{C}+\mathrm{Jr} . \&$ Title $=\% 22 \mathrm{The}+$ role + of + upstream + lakes $\% 22 \&$ pubnum $=$.

Saslo, S., and S. Greybush, 2017: Prediction of lake-effect snow using convection-allowing ensemble forecasts and regional data assimilation. Wea. Forecasting, 32, 1727-1744, https:// doi.org/10.1175/WAF-D-16-0206.1.

Schroeder, J. J., D. A. Kristovich, and M. R. Hjelmfelt, 2006: Boundary layer and microphysical influences of natural cloud seeding on a lake-effect snowstorm. Mon. Wea. Rev., 134, 1842-1858, https://doi.org/10.1175/MWR3151.1.

Sousounis, P. J., and H. N. Shirer, 1992: Lake aggregate mesoscale disturbances. Part I: Linear analysis. J. Atmos. Sci., 49, 80-96, https:// doi.org/10.1175/1520-0469(1992)049<0080:LAMDPI>2.0.CO;2.

__- and G. E. Mann, 2000: Lake-aggregate mesoscale disturbances. Part V: Impacts on lake-effect precipitation. Mon. Wea. Rev., 128, 728-745, https://doi.org/10.1175/ 1520-0493(2000)128<0728:LAMDPV>2.0.CO;2.

Steenburgh, W. J., and D. J. Onton, 2001: Multiscale analysis of the 7 December 1998 Great Salt Lake-effect snowstorm. Mon. Wea. Rev., 129, 1296-1317, https://doi.org/10.1175/15200493(2001)129<1296:MAOTDG > 2.0.CO;2.

, and L. S. Campbell, 2017: The OWLeS IOP2b lake-effect snowstorm: Shoreline geometry and the mesoscale forcing of precipitation. Mon. Wea. Rev., 145, 2421-2436, https://doi.org/ 10.1175/MWR-D-16-0460.1.

Stull, R. B., 1988: An Introduction to Boundary Layer Meteorology. Kluwer Academic, 666 pp.

Suriano, Z. J., and D. J. Leathers, 2017: Synoptic climatology of lake-effect snowfall conditions in the eastern Great Lakes region. Int. J. Climatol., 37, 4377-4389, https://doi.org/10.1002/ joc.5093.

Theeuwes, N. E., G. J. Steeneveld, F. Krikken, and A. A. M. Holtslag, 2010: Mesoscale modeling of lake effect snow over Lake Erie-Sensitivity to convection, microphysics, and the water temperature. Adv. Sci. Res., 4, 15-22, https://doi.org/ 10.5194/asr-4-15-2010.

Tripoli, G. J., 2005: Numerical study of the 10 January 1998 lakeeffect bands observed during Lake-ICE. J. Atmos. Sci., 62, 3232-3249, https://doi.org/10.1175/JAS3462.1.

Wang, Z., and Coauthors, 2012: Single aircraft integration of remote sensing and in situ sampling for the study of cloud microphysics and dynamics. Bull. Amer. Meteor. Soc., 93, 653-668, https://doi.org/10.1175/BAMS-D-11-00044.1.

Wright, D. M., D. J. Posselt, and A. L. Steiner, 2013: Sensitivity of lake-effect snowfall to lake ice cover and temperature in the Great Lakes region. Mon. Wea. Rev., 141, 670-689, https:// doi.org/10.1175/MWR-D-12-00038.1.

Young, G. S., and T. D. Sikora, 2003: Mesoscale stratocumulus bands caused by Gulf Stream meanders. Mon. Wea. Rev., 131, 2177-2191, https://doi.org/10.1175/1520-0493(2003)131<2177: MSBCBG $>2.0 . \mathrm{CO} ; 2$.

Yuen, C., and J. A. Young, 1986: Dynamical adjustment theory for boundary layer flow in cold surges. J. Atmos. Sci., 43, 3089-3108, https://doi.org/10.1175/1520-0469(1986)043<3089: DATFBL $>2.0 . \mathrm{CO} ; 2$. 